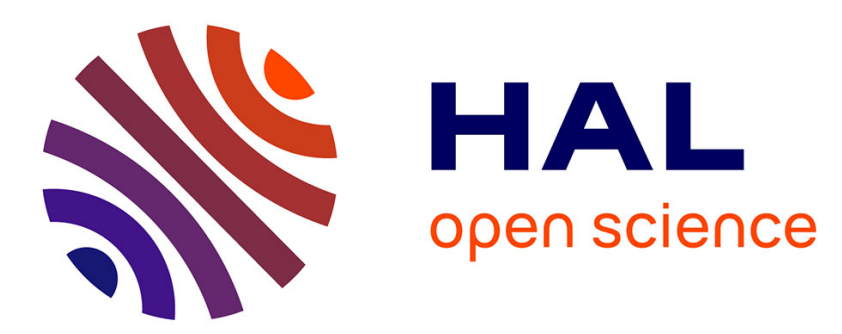

\title{
Behaviors of extreme water level in the Pearl River Delta and possible impacts from human activities
}

\author{
Y. D. Chen, Q. Zhang, T. Yang, C. Xu, X. Chen, T. Jiang
}

\section{To cite this version:}

Y. D. Chen, Q. Zhang, T. Yang, C. Xu, X. Chen, et al.. Behaviors of extreme water level in the Pearl River Delta and possible impacts from human activities. Hydrology and Earth System Sciences Discussions, 2007, 4 (6), pp.4361-4387. hal-00298917

\section{HAL Id: hal-00298917 https://hal.science/hal-00298917}

Submitted on 5 Dec 2007

HAL is a multi-disciplinary open access archive for the deposit and dissemination of scientific research documents, whether they are published or not. The documents may come from teaching and research institutions in France or abroad, or from public or private research centers.
L'archive ouverte pluridisciplinaire HAL, est destinée au dépôt et à la diffusion de documents scientifiques de niveau recherche, publiés ou non, émanant des établissements d'enseignement et de recherche français ou étrangers, des laboratoires publics ou privés. 
Hydrol. Earth Syst. Sci. Discuss., 4, 4361-4387, 2007 www.hydrol-earth-syst-sci-discuss.net/4/4361/2007/

(C) Author(s) 2007. This work is licensed under a Creative Commons License.
Hydrology and

Earth System

Sciences

Discussions

Papers published in Hydrology and Earth System Sciences Discussions are under open-access review for the journal Hydrology and Earth System Sciences

\section{Behaviors of extreme water level in the Pearl River Delta and possible impacts from human activities}

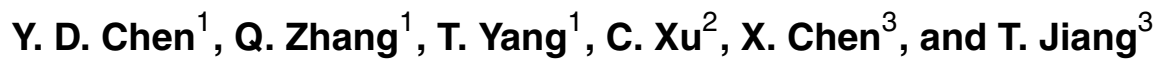

${ }^{1}$ Department of Geography and Resource Management and Institute of Space and Earth Information Science, The Chinese University of Hong Kong, Shatin, Hong Kong, China

${ }^{2}$ Department of Geosciences, University of Oslo, Oslo, Norway

${ }^{3}$ Department of Water Resources and Environment, Sun Yat-sen University, Guangzhou, 510275, China

Received: 13 November 2007 - Accepted: 20 November 2007 - Published: 5 December 2007 Correspondence to: Q. Zhang (qiangzhang@ cuhk.edu.hk)

Extreme tidal levels in the Pearl River Delta

Y. D. Chen et al.

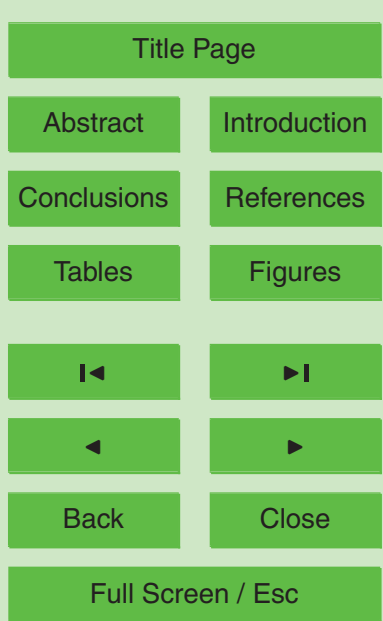

Printer-friendly Version

Interactive Discussion 


\section{Abstract}

Trends and variations of the extreme water levels defined as exceeding/falling below certain thresholds (mean \pm std) across the Pearl River Delta (PRD) are systematically explored using the linear regression method. Research results indicate that: 1) The 5 upper PRD is dominated by the significant decreasing low water level, and significant increasing low water level can be identified in the lower PRD. The variations of the relative frequency of the high water level are characterized by the decreasing variability in the middle PRD. However more stations show significant changes of the relative frequency of the low water level across the PRD. No confirmative changing patterns of the relative frequency of the low water level can be detected in the middle PRD; 2) When it comes to the seasonal variations of the high/low water level in JJA (high flow periods in the PRD), stations located closer to the estuary tend to exhibit increasing high/low water level. However stations located closer to the upper PRD tend to show decreasing high/low water level. Similar patterns can be identified in the high/low water 15 level in DJF (low flow periods in the PRD); 3) The changes of the water level in the PRD are heavily affected by human interferences, e.g. in-channel dredging, sand mining and the construction of levees. The stations dominated by decreasing water level are mostly located along the river channels featured by highly-intensive dredging. The stations along the coastal regions show significant increasing extreme high/low water level. The coastal regions are not influenced by in-channel dredging, and furthermore, sediment loads from upper and middle PRD are deposited in the river mouths and which will tend to raise the water level in the estuary of the PRD. The findings of this paper may be helpful for local water resource management.

\section{Introduction}

25 River Deltas are natural dynamic coastal systems that are unique in their close links to both land-based fluvial and coastal ocean processes. The deltas hold the ecolog-
HESSD

4, 4361-4387, 2007

\section{Extreme tidal levels in the Pearl River Delta}

Y. D. Chen et al.

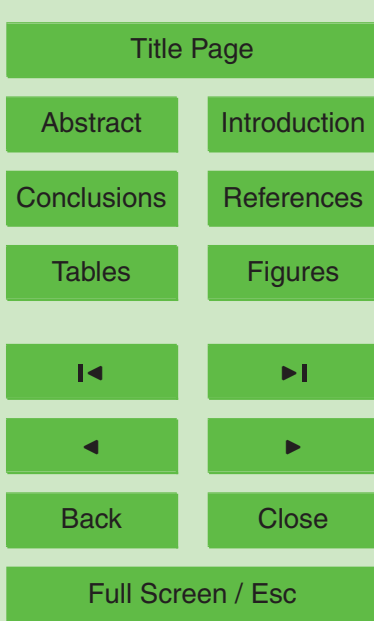

Printer-friendly Version

Interactive Discussion 
ical and economic value throughout the world and are major centers of population and agriculture (Ericson et al., 2006; Pont et al., 2002). The river deltas are usually level plain with smaller elevation above the sea level, which makes the deltas prone to flooding and sea level changes (Zhang et al., 2005). Ericson et al. (2006) has as5 sessed the contemporary effective sea-level rise for a sample of 40 deltas distributed worldwide, suggesting that the population and area inundated rise significantly when considering increased flood risk due to storm surge. Furthermore, the salinity intrusion resulted from extreme water level and less streamflow from the upper river delta will exert negative impacts on the human use of the water resource. Mao et al. (2004) indi10 cated that the Pearl River estuary showed a typical salt wedge circulation: a salt water intrusion largely occurred via the eastern channel in the estuary while river outflow dominated the western channel. Higher water level in the estuary, lower water level and less streamflow in the eastern river channels will result in serious salinity intrusion and which will influence the human use of freshwater in the Pearl River Delta. The 15 vulnerability of the ecological environment and social economy in the PRD will be increasing with the flourishing development of the local social economy and fast growth of population, which will be further intensified if compounded by the global historical trend in eustatic sea-level rise and predictions of increasing rates of sea-level over the next century (Church and Gregory, 2001).

20 The crisscross river network (density: $0.68-1.07 \mathrm{~km} / \mathrm{km}^{2}$ ) in the PRD is one of the most complicated deltaic drainage systems in the world (Chen and Chen, 2002). Represented by the "Golden Triangle" of Zhuhai-Hong Kong-Macau, the PRD has a highly dense agglomeration of over 100 towns and cities. It has been the fastest developing region in China since the country adopted the "open door and reform" policy in the late

25 1970s. On less than $0.5 \%$ of the country's territory, the PRD region produces about $20 \%$ of the national GDP, attracts about $30 \%$ of Foreign Direct Investment, and contributes about $40 \%$ of export (therefore called "World Factory"). Highly developed social economy makes the PRD vulnerable to flood, drought, and other natural hazards. Moreover, increasingly intensified human activities resulted in considerable hydrolog-

HESSD

4, 4361-4387, 2007

\section{Extreme tidal levels in the Pearl River Delta}

Y. D. Chen et al.

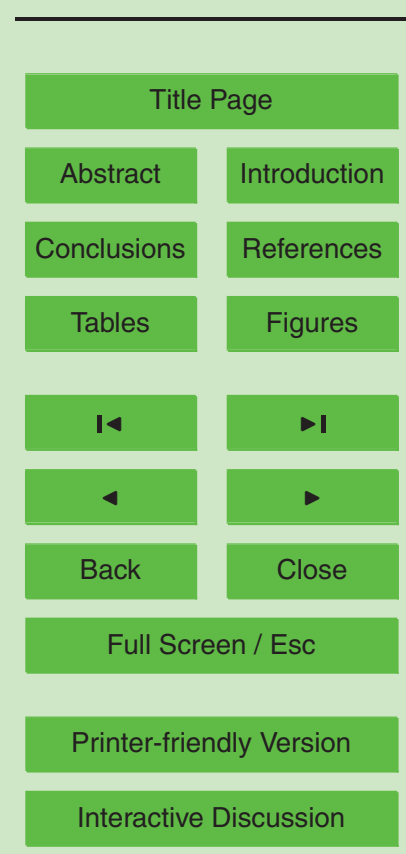

EGU 
ical alterations in the Pearl River Delta. After about 1980s, human interferences and impacts of sea-level variations on hydrological processes in the PRD are: 1) intensive in-channel dredging and sand mining, which caused significant in-channel geomorphological alterations and breaks the natural balance of the filling-scouring process within 5 the river channels; 2) re-allocation of the streamflow and sediment loads within the river channels of the Pearl River Delta because of construction of levees and sand dredging; 3) increasing sea level in the estuary leading to the backwater effect, which further intensifies the prevalent sediment deposition in the river mouths and results in the salinity intrusion in the Pearl River Delta. The salinity intrusion, frequent floods, water logging, 10 and typhoon are the key factors negatively influencing the sustainable development of the local social economy and ecological environment in the PRD. Many researches concerning the water levels and possible causes can be found in Chinese literatures (e.g. Luo et al., 2000; Liu et al., 2003; Chen et al., 2004; Yang et al., 2002; Huang et al., 2000). Research results indicated that the hydrological alteration occurred to the PRD after about 1993. The river channels in the upper PRD are deepened greatly because of in-channel sand dredging after 1980s, accelerating the flow velocity and resulting in decreasing water level. Furthermore, the sea level in the estuary is increasing, leading to obvious backwater effect and the increasing water level. All these factors, together with the construction of the levees, result in the re-allocation of the streamflow and the sediment loads within the river networks and lead to the abrupt changes of the water level (Xu, 1998; Li, 2001). However, several scientific problems are still kept unanswered: 1) What are the variations of water levels, especially the so-called extreme water levels defined as water levels exceeding/falling below priori determined thresholds? 2) What are the possible characteristics of these variations detected in different parts of the PRD? 3) What are the possible causes underlying these variations of the extreme water levels across the PRD? In addition, it should be mentioned herein that greater impacts of extreme hydrological events on human populations are more likely to accrue through changes in the frequency of extreme events than through slow changes in mean conditions (e.g. Wigley, 1985). Therefore, public awareness
HESSD

4, 4361-4387, 2007

\section{Extreme tidal levels in the Pearl River Delta}

Y. D. Chen et al.

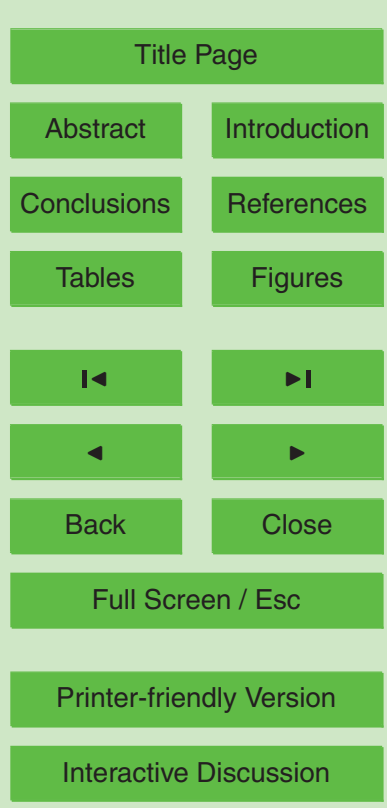

EGU 
of extreme events has risen sharply in recent years partly because tremendous concerns are drawn on the catastrophic nature of floods, droughts, storms, typhoon and the sea-level rise (e.g. Beniston and Stephenson, 2004; Zhang et al., 2006, 2007). Extreme high/low water levels are closely associated to flood hazards and the salin5 ity intrusion, which play the paramount role in the local water resource management practice. Therefore the trends of the frequency of extreme water levels defined as the times of the water levels exceeding/falling below priori determined thresholds defined as mean \pm std within certain time intervals will be discussed using linear regression method. The objectives of this paper are: 1) to detect trends and variations of the 10 frequency extreme water levels over certain time intervals (relative frequency); 2) to explore the spatial patterns of the relative frequency trends of extreme water levels and possible underlying causes. Findings drawn from studying the behaviors of water levels across the PRD may be useful for the local water resource management and the human adaptation to the flood, drought, sea level rising, salinity intrusion and typhooninduced flood hazards under the changing environment and climatic changes in the Pearl River Delta, as one of the economically developed regions in China, thereby, a system of mitigating measures can be designed to avoid the negative impacts of such events.

\section{Study region and data}

\subsection{The study region}

The Pearl River basin involves the West River, the North River, the East River and the rivers within the Pearl River Delta, with total drainage area of $453690 \mathrm{~km}^{2}$. The Pearl River Delta (Fig. 1) is the integrated delta composed of West River delta, North River delta and East River delta. The area of the Pearl River Delta is about $9750 \mathrm{~km}^{2}$, wherein the West River delta, the North River delta account for about $93.7 \%$ and the East River delta accounts for $6.6 \%$ of the total area of the Pearl River Delta. The Pearl
HESSD

4, 4361-4387, 2007

\section{Extreme tidal levels in the Pearl River Delta}

Y. D. Chen et al.

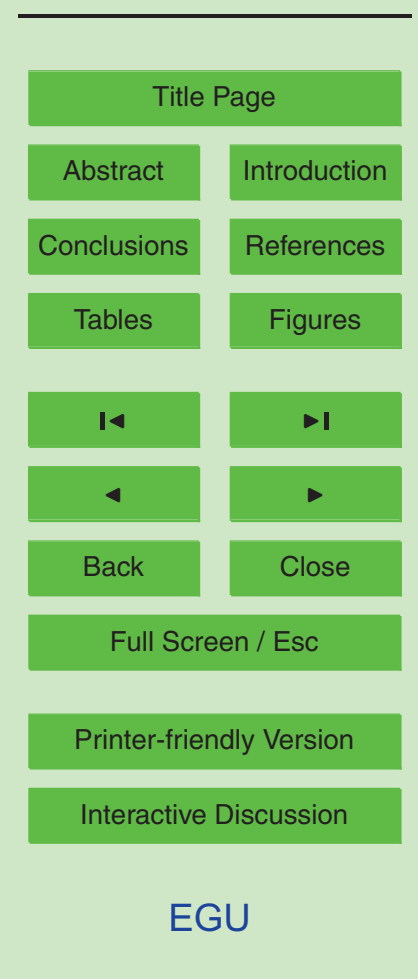


River Delta is controlled by the south sub-tropical monsoon climate with abundant precipitation. The multi-annual mean precipitation is $1470 \mathrm{~mm}$ and the precipitation mainly occurred during April-September. The "open door and reform" policy in the late 1970s leads to the thriving social economic development, with the fastest economic develop5 ment of the PRD the intensifying human activities greatly impacted the natural features of the river network within the PRD. In about 1970s, the construction of levees and other modifications of the river channels in the PRD, e.g. dredging, sand mining aiming to provide flood protection and to provide building materials greatly altered natural conditions of the river channel, which breaks the in-channel filling-scouring balance. The 10 direct results of the intensifying human activities are upward flood stage and also the repeated large magnitude floods in recent years. Therefore, further understanding of the water level changes under different magnitudes of flow within the PRD and changing climate will be greatly helpful for local water resource management and human mitigation to natural hazards over the PRD.

\subsection{Data}

The monthly data of the extreme water level covering 1958-2005 were collected from 23 gauging stations in the Pearl River Delta. Detailed information of the data used in the current research can be referred to Table 1 and the location of the gauging stations can be found in Fig. 1. The lengths of the data are various. Some stations have missing 20 data during certain time intervals (Table 1). The missing data exerted less influences on the results based on the objectives of this study. Therefore the missing data were left alone in the current research.

\section{Methods}

The current research focuses on the extreme monthly water levels (the monthly highest/lowest water levels), because the extreme high/low water levels are closely related

\section{HESSD}

4, 4361-4387, 2007

\section{Extreme tidal levels in the Pearl River Delta}

Y. D. Chen et al.

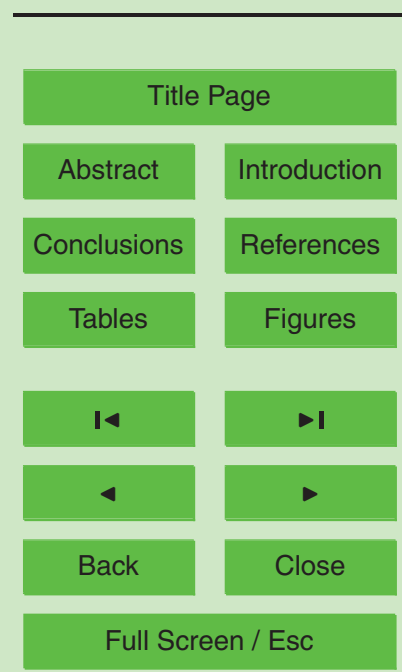

Printer-friendly Version

Interactive Discussion 
to the floods, salinity intrusion, which have the paramount role to play in the local water resource management and human mitigation to flood hazards in the Pearl River Delta. The extreme water levels are defined as those exceeding/falling below a given threshold (known as partial duration series). This method is also called as the PD analysis 5 (or peaks over threshold, POT), which considers all the values of the variable that exceed/fall below an a priori determined threshold (Bordi et al., 2006). In PD analysis, we are interested in the behavior of large numbers of observations that exceed/fall below a priori threshold. The thresholds decided herein are two cases, i.e. mean \pm std, which can be applied for better comparison between the data collected before and after the 10 possible abrupt changes resulted from intensive human activities which are common in the PRD (e.g. Yoo, 2006). The thresholds are summarized in Table 2. The trends of the observed number of occurrences of extreme water levels exceeding/falling below certain thresholds spanning a certain time interval (refers to one year in this paper) will be detected by the simple linear regression method. The simple linear regression method used in the current study is a parametric T-test method, which consists of two steps, fitting a linear simple regression equation with the time $t$ as independent variable and the hydrological variable (in this case the monthly extreme water level), $Y$ as dependent variable, and testing the statistical significance of the slope of the regression equation. The confidence level of $95 \%$ will be accepted in the current study. The parametric T-test requires the data to be tested is normally distributed. The normality of the data series is first tested in the study by applying the Kolmogorov-Smirnov test $(\mathrm{Xu}, 2001)$. The method first compares the specified theoretical cumulative distribution function (in our case normal distribution) with the sample cumulative density function based on observations, then calculates the maximum deviation, $D$, of the two. If, for the chosen significance level, the observed value of $D$ is greater than or equal to the critical tabulated value of the Kolmogorov-Smirnov statistic, the hypothesis of normal distribution is rejected. The changing patterns of the frequency of the extreme water levels in certain time intervals are identified by the moving average method.
HESSD

4, 4361-4387, 2007

\section{Extreme tidal levels in the Pearl River Delta}

Y. D. Chen et al.

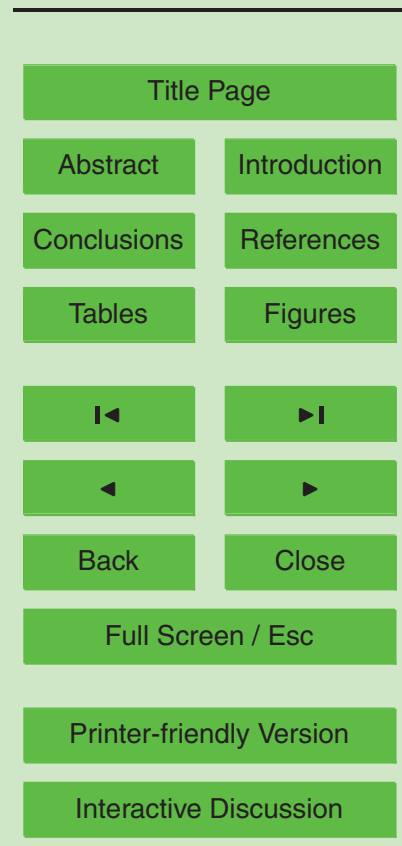

EGU 


\section{Results}

\subsection{Annual variability of extreme water levels}

Figure $2 \mathrm{a}$ demonstrates linear trends of the relative frequency of the extreme high water level above mean + std threshold (HWLa). It can be seen from Fig. 2a that the 5 HWLa of majority of the stations in the Pearl River Delta (PRD) is decreasing, and these stations are mostly located in the middle and upper PRD (see regions circled by the dashed line). The stations with decreasing HWLa account for about $59 \%$ of the total stations in the PRD. However, only 4 stations have the significant decreasing HWLa, accounting for about $30 \%$ of the total stations with decreasing HWLa. The stations with increasing HWLa are located sparsely along the coastal regions of the lower PRD (Fig. 2a, Fig. 1). Statistically speaking, if the trend of the time series is not significant at the priori defined confidence level (95\% confidence level in this study), the time series is suggested to be in no trend. Therefore, the HWLa of most stations of the PRD is not in significant trend. 8 stations have significant trend of the HWLa, accounting for $34.8 \%$ of the total stations of the PRD. Figure $2 \mathrm{~b}$ shows the linear trends of the relative frequency of the extreme water level defined as those falling below mean - std threshold (HWLb). Most stations in the PRD are dominated by the decreasing HWLb. The decreasing HWLb are mainly identified across the middle and lower PRD. Only 6 stations are featured by the increasing HWLb, accounting for $18 \%$ of the total 20 stations. The majority of the stations are dominated by significant trend of the HWLb, accounting for $65 \%$ of the total stations of the PRD. The significant trend of the HWLb is largely identified in the upper and middle PRD.

Figure 2c displays the linear trends of the relative frequency of the extreme water levels defined as extreme low water levels exceeding mean + std threshold (LWLa). 25 It can be seen from Fig. $2 c$ that the PRD is dominated by the significant decreasing LWLa, and the stations with decreasing LWLa are uniformly distributed across the PRD. The stations with decreasing LWLa account for about $59 \%$ of the total stations of the PRD. The upper PRD, middle PRD and parts of the lower PRD are dominated by 4368
HESSD

4, 4361-4387, 2007

\section{Extreme tidal levels in the Pearl River Delta}

Y. D. Chen et al.

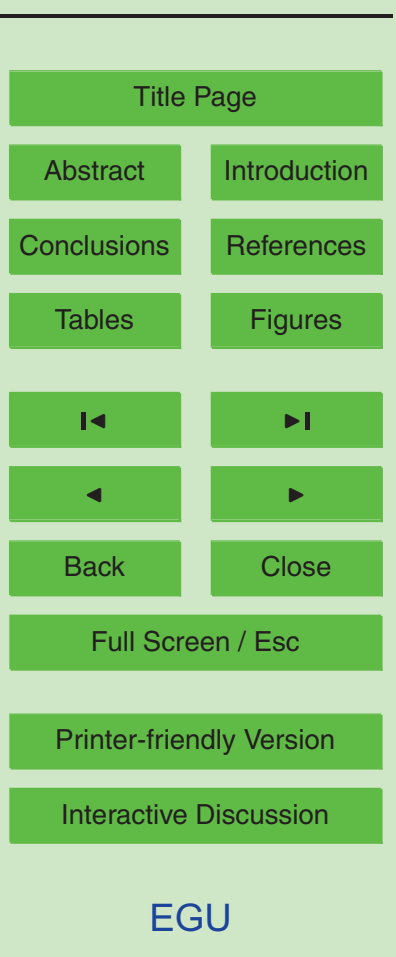


significant trend of the LWLa. The significant increasing LWLa is identified mainly along the coastal regions. The upper PRD is dominated by the significant decreasing LWLa. 3 stations have significant decreasing LWLa, i.e. Zhuyin, Xipaotai and Denglongshan. No trend can be detected in the LWLa of Rongqi, Xiaolan, Tianhe and Huangpu in 5 the middle PRD and along the Qianhangxian channel and Ronggui channel (Fig. 1). Figure $2 \mathrm{~d}$ displays the linear trends of the relative frequency of the extreme water level defined as the extreme low water level falling below mean - std threshold (LWLb). Figure $2 \mathrm{~d}$ demonstrates the irregular patterns of the LWLb variations over the PRD. It can be seen from Fig. $2 d$ that the upper PRD is dominated by significant increasing 10 LWLb, however the significant decreasing LWLb can be identified in the lower PRD. 3 stations in the lower PRD are featured by significant increasing LWLb, i.e. Xipaotai, Zhuyin and Denglongshan. The middle PRD seems to be a transitional zone with significant increasing LWLb and significant decreasing LWLb. However majority of the stations have significant increasing LWLb, accounting for $55.6 \%$ of the total stations in 15 the middle PRD.

Table 3 shows the summary of the results of Fig. 2. Table 3 suggests that the upper PRD is dominated by significant decreasing high water level and low water level, high water level of Sanshui and Makou exhibits decreasing variability. The high water level of the middle PRD is dominated by decreasing variability. Significant decreasing high water level can be identified in Jiangmen located along the lower Xijiang Channel. However significant decreasing low water level prevails in the middle PRD. Significant decreasing low water level is detected in 4 stations of the middle PRD, accounting for $57 \%$ of the total stations in the middle PRD. The high water level in the lower PRD also exhibits decreasing variability, similar to the middle PRD. 3 stations are dominated

by significant increasing high water level, i.e. Hengmen, Sishengwei and Xipaotai; one station has significant decreasing high water level, i.e. Sanshakou. The lower PRD is dominated by significant increasing low water level. Significant increasing low water level is detected in 6 stations, accounting for $50 \%$ of the stations in the lower PRD. Significant decreasing low water level can be identified in 4 stations, accounting for
HESSD

4, 4361-4387, 2007

\section{Extreme tidal levels in the Pearl River Delta}

Y. D. Chen et al.

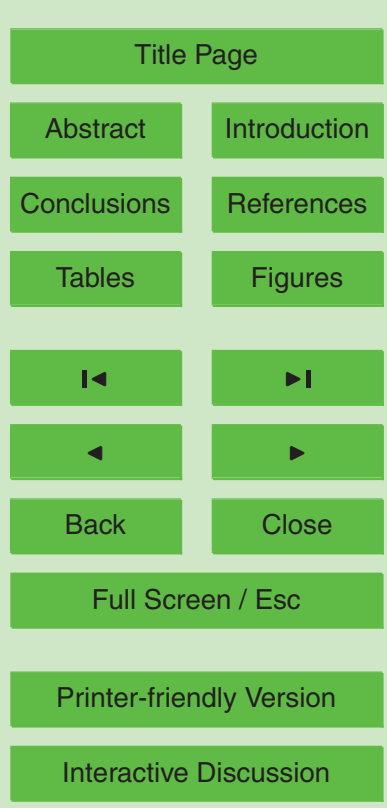

EGU 


\subsection{Variability of the extreme water levels in JJA and DJF}

The high flow usually occurs to June, July and August (JJA) and low flow usually occurs to December, January and February (DJF). High water levels are closely associated 5 with the high flow and lower water levels are usually in close relation to the low flow. High flow and high water levels tend to result in floods; low flow and low water levels are related to droughts and salinity intrusion. The low flow, higher tidal level and stronger tidal current combine to cause higher probability of the salinity intrusion in the hinterland of the PRD. Thereby, we explore the behaviors of the extreme water levels in

10 JJA and DJF. Figure 3 demonstrates the linear trends of the HWLa (Fig. 3a) and LWLa (Fig. 3b) in JJA. The HWLb and LWLb in JJA can not be detected. It can be seen from Fig. $3 a$ that the HWLa in JJA is not significant at $>95 \%$ confidence level. The trend of the HWLa of three stations in JJA is significant at $>95 \%$ confidence level, i.e. Xipaotai, Hengmen and Shilong. The trend of the HWLa of the rest stations is not significant at $5>95 \%$ confidence level.

Figure $3 \mathrm{~b}$ demonstrates similar changing patterns of LWLa when compared to those of HWLa (Fig. 3a). It can be seen from Fig. 3b that majority of the stations are dominated by decreasing LWLa and most of these stations are located in the upper and middle PRD. In comparison with what is shown in Fig. 3a, the LWLa of more stations

are in significant trends. Most stations located in the lower PRD have significant trends of LWLa. The LWLa of majority of stations located in the lower PRD exhibits significant increasing trend of LWLa. The stations with significant increasing LWLa account for $62.5 \%$ of total stations with significant LWLa trend. The PRD is dominated by the decreasing LWLa in summer (Fig. 3b). The variations of the LWLa in upper and middle

LWLa can also be identified in upper and middle PRD.

Figure 4 shows the linear trends of HWLb (Fig. 4a) and LWLb (Fig. 4b) in DJF. It can be seen from Fig. $4 a$ that a majority of the PRD is dominated by decreasing

HESSD

4, 4361-4387, 2007

\section{Extreme tidal levels in the Pearl River Delta}

Y. D. Chen et al.

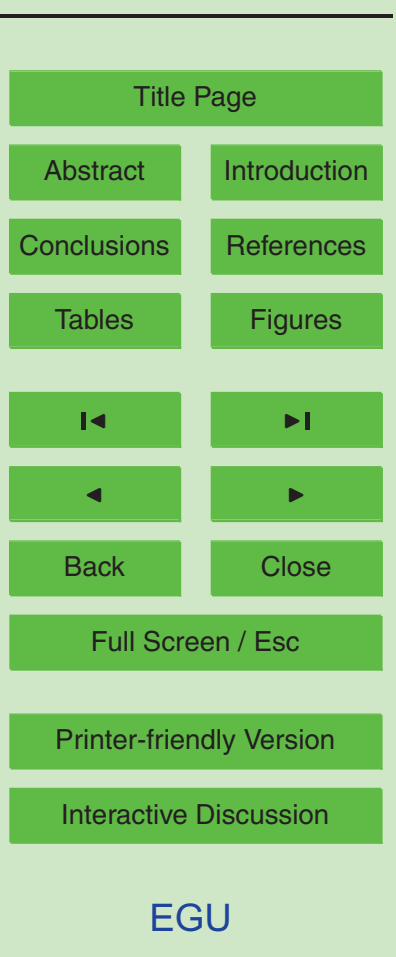


HWLb. However the HWLb of only 8 stations exhibits significant trends. These stations distributed uniformly across the PRD. No confirmative spatial patterns of trends of the HWLb can be identified in the PRD. The HWLb of the majority of the stations of the PRD exhibits not significant trends. LWLb manifests different changing patterns when 5 compared to those of HWLb as demonstrated in Fig. 4a. It can be seen from Fig. 4b that most stations of the PRD show significant trend of LWLb. The upper PRD is dominated by the significant increasing HWLb in DJF. The LWLb in the middle PRD exhibits complicated spatial patterns. In the middle PRD, wo stations (Jiangmen and Xiaolan) show significant increasing LWLb and two stations (Tianhe and Shizui) exhibit 10 significant decreasing LWLb. Three stations (Huangpu, Nanhua and Rongqi) show not-significant changes of the LWLb. However the lower PRD is dominated by the significant decreasing LWLb. The stations with significant decreasing LWLb account for $70 \%$ of the stations with significant LWLb trends in the lower PRD. Three stations (Sanshakou, Zhuyin and Xipaotai) in the lower PRD exhibit significant increasing LWLb 15 (Fig. 4b).

\section{Summary and discussions}

Changes of the extreme high water level are in close relation with flood hazards and the extreme low water levels are closely associated with the salinity intrusion in the PRD region, and these two aspects play considerable roles in the local water resource management, human mitigation to flood hazards. Linear regression method is performed on the extreme water levels defined as water levels exceeding/falling below certain thresholds, i.e. mean \pm std. Interesting results and conclusion are drawn as follows:

1) The relative frequency of the high water level exhibits changes not significant at $>95 \%$ confidence level. The variations of the relative frequency of the high water level are characterized by the decreasing variability, especially in the middle PRD. The significant increasing frequency of the high water level occurred in the south mainstem East River channel, the Hengmen channel and the Hutiaomen channel. However more

HESSD

4, 4361-4387, 2007

\section{Extreme tidal levels in the Pearl River Delta}

Y. D. Chen et al.

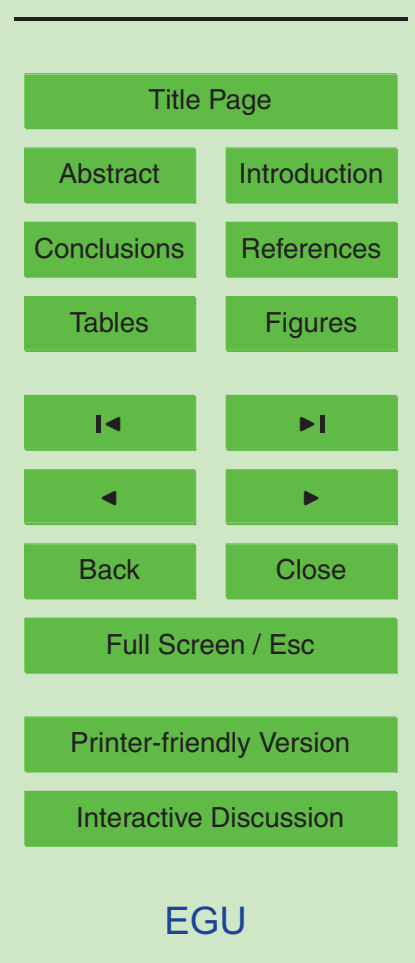


stations show significant changes of the relative frequency of the low water level across the PRD. The upper PRD is dominated by the significant decreasing trend of the lower water level, and significant increasing low water level can be identified in the lower PRD. No confirmative changing patterns of the relative frequency of the low water level 5 can be detected in the middle PRD. As for the high water level and lower water level in JJA (high flow periods in the PRD), stations located closer to the estuary tend to show increasing high/low water level. However stations located closer to the upper PRD tend to show decreasing high/low water level. Moreover, more stations exhibit significant changes of the low water level than those show significant changes of the 10 high water level, which may indicate that low water level may be more sensitive to human interference and to impacts from climate changes, e.g. precipitation changes. Similar patterns can be identified in the high/low water level in DJF (low flow periods in the PRD). More stations show significant changes of low water level when compared to those stations show significant changes of the low water level in DJF. In addition, the 15 spatial patterns of the changes of the water level in DJF seem to be complicated when compared to those of water level in JJA, which also indicates that changes of the low water level may be more sensitive to human interferences and climate changes when compared to the changes of the high water level

2) Wang et al. (2006) indicated that upper West River basin is dominated by decreasing precipitation, especially in summer and autumn. Increasing precipitation however is identified in the North River basin and the East River basin. The summer precipitation in the North River basin is decreasing. After about 1990s, distinct riverbed downcutting occurred to the mainstem North River, which is in close association with the intense dredging and sand mining. This downcutting of the riverbed caused distinct decreasing of the water level of the Sanshui station. Moreover, the magnitude of the decreasing water level of the Sanshui station is much more than that of the Makou station, resulting in significant decreasing Makou/Sanshui streamflow ratio and more streamflow was transferred to the river channel controlled by the Sanshui station. The changing Makou/Sanshui streamflow ratio further altered the spatial and temporal alterations of
HESSD

4, 4361-4387, 2007

\section{Extreme tidal levels in the Pearl River Delta}

Y. D. Chen et al.

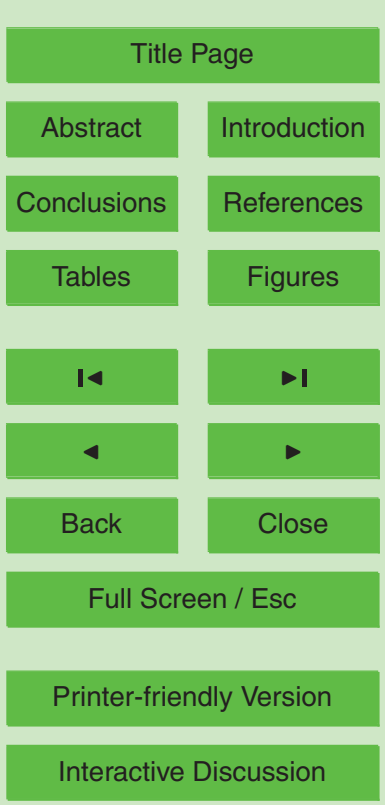

EGU 
the water level in the streamflow-impacted river channels. Close relationships should be held between streamflow and water level; high flow is usually associated with high water level, and vice versa. However research results of this paper indicates that the upper PRD is dominated by decreasing high/low water level. The area of the West 5 River basin and the North River basin accounts for about $88 \%$ of the Pearl River basin. The streamflow changes of the PRD delta are controlled mainly by the streamflow changes of the Sanshui and Makou station. The rivers with water levels affected by the streamflow from the Sanshui and Makou station cover the most parts of the middle and lower PRD. Therefore, it is reasonable to focus on the relations between water levels 10 of the PRD and the streamflow of the Sanshi and Makou station. Table 3 indicates that good correlations are kept between high flow and high water levels of the most of the stations in the upper and middle PRD $(R \geq 9)$, showing the tremendous impacts of the hydrological processes from the upper PRD on the water levels in the upper and middle PRD. However, bad correlations are kept between high flow and high water levels in 15 the lower PRD $(R \leq 0.73)$. Moreover, correlations between low flow and low water level are not good relative to those between high flow and high water level, showing the considerable impacts of the tidal level changes on the water level changes in the low flow season across the PRD. The water levels in the middle PRD do not demonstrate confirmative changing patterns. The lower PRD is dominated by increasing low water levels.

20 The high water levels demonstrate not distinct patterns. With the intensifying human activities, the changes of the water level in the PRD are heavily impacted by human interferences, e.g. in-channel dredging, sand mining and the construction of levees. Figure 8 demonstrates the river channels featured by different intensities of dredging and different parts of the PRD impacted by different hydrological dynamic factors: the 25 upper PRD is mainly influenced by streamflow from the East River, North Rive and the West River; the middle PRD is influenced by both the riverine streamflow and the tidal current; the lower PRD are mainly influenced by tidal current. Figure 8, together with Figs. 2, 3 and 4, indicates that the stations dominated by decreasing water level are mostly located along the river channels featured by intensive sand dredging. The

HESSD

4, 4361-4387, 2007

\section{Extreme tidal levels in the Pearl River Delta}

Y. D. Chen et al.

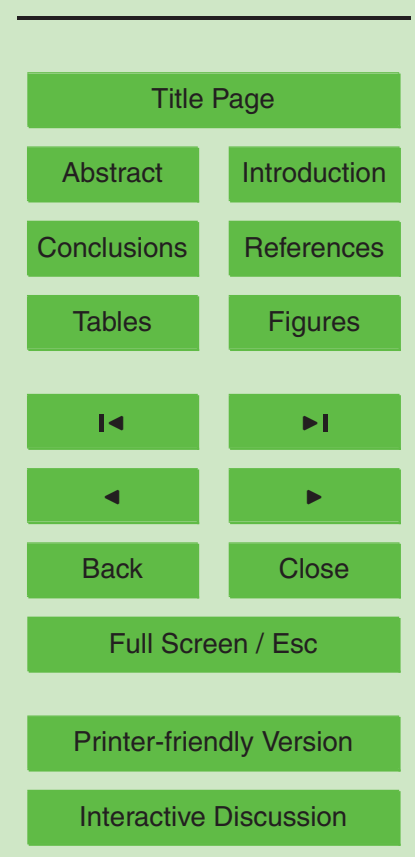

EGU 
water level in the PRD influenced by both streamflow and tidal levels is in somewhat complicated changing characteristics. The stations along the coastal regions show significant increasing extreme high/low water level. The coastal regions are not influenced by sand dredging, and furthermore, sediment loads from upper and middle PRD are 5 deposited in the river mouth and which will be beneficial for rise of the water level in the estuary of the PRD. The water level in the Modaomen channel is decreasing, highly and sub-highly sand dredging occurred to the Modaomen channel resulting in the decreasing water level in the Modaomen, which elucidates well the paramount impacts of human activities, e.g. the in-channel sand dredging, on the water level changes in the 10 PRD. Results of this paper also suggest that the responses of the low water level to external interferences are more distinct and sensitive when compared to those of high water level, because more stations are with significant changes of low water level than those with significant changes of the high water level.

3) Changes of the water level across the PRD are heavily influenced by human ac15 tivities, especially by the in-channel sand dredging. The construction of the levee may aggregate streamflow in the channel and which may be beneficial for the rising of water level. However, more streamflow in the channels will lead to more serious scouring process and deepening of the river channel, which will lead to the decreasing water level. This offset effect will be changing in different river channels and will also be influenced by different intensities of the in-channel dredging and sand mining. The different roles of the sand dredging and the construction of levees in tidal alterations within the river channels in the PRD are necessary for further research in the future. The research of this paper indicates that increasing water level is usually identified in the channel featured by moderate and low intensity of the dredging. River channels featured by ter levels. Decreasing trends and smaller variability range are identified in the water levels in the middle PRD and increasing trends of water level are detected in the lower PRD. Therefore the salinity intrusion should be paid enough attention in the local water resource management. In the current research, only impacts of human activities on the
HESSD

4, 4361-4387, 2007

\section{Extreme tidal levels in the Pearl River Delta}

Y. D. Chen et al.

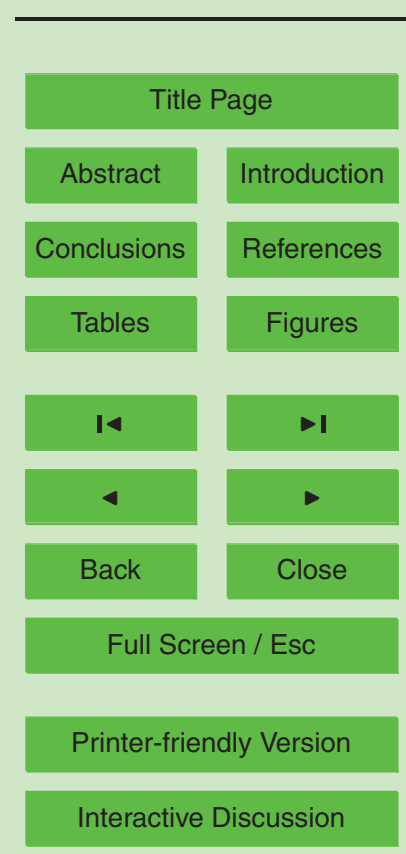

EGU 
changes of the water level are discussed. It should be noted herein that the climatic changes (precipitation changes and changes of the streamflow from upper PRD) and sea level changes also exert tremendous impacts on the spatial and temporal variability of the water levels in the PRD. In addition, when do the abrupt changes occur? And 5 what are the statistical features for the water levels before/after the change points? All these questions will be addressed in the further research.

Acknowledgements. The work described in this paper was fully supported by a grant from the Research Grants Council of the Hong Kong Special Administrative Region, China (Project No. CUHK4627/05H), fully supported by a Direct Grant from the Faculty of Social Science, 10 The Chinese University of Hong Kong (Project No. 4450183) and financially supported by the Outstanding Overseas Chinese Scholars Fund from CAS (The Chinese Academy of Sciences).

\section{References}

Beniston, M. and Stephenson, D. B.: Extreme climatic events and their evolution under changing climatic conditions, Global Planet. Change, 44, 1-9, 2004.

15 Bordi, I., Fraedrich, K., Petitta, M., and Sutera, A.: Extreme value analysis of wet and dry periods in Sicily, Theor. Appl. Climatol., doi:10.1007/s00704-005-0195-3, 2006.

Chen, X. H. and Chen, Y. Q.: Hydrological change and its causes in the river network of the Pearl River Delta, Acta Geographica Sinica, 57(4), 430-436, 2002 (in Chinese).

Chen, X. H., Zhang, L., and Shi, Z.: Study on spatial variability of water levels in river net of Pearl River Delta, Shuili Xuebao, 10, 36-42, 2004 (in Chinese).

Church, J. and Gregory, J. M.: Changes in sea-level, in: Climate Change 2001: the Scientific Basis, Contribution of Working Group 1 to the Third Assessment Report of the Intergovernmental Panel on Climate Change, edited by: Houghton, I. T., Ding, Y., Griggs, D. J., Noguer, M., van der Linden, P. J., Dai, X., Maskell, K., and Johnson, C. A., Cambridge University Press, Cambridge, 2001.

Ericson, P. J., Vörösmarty, J. C., Dingman, L. S., Ward, G. L., and Meybeck, M.: Effective sealevel rise and deltas: Causes of change and human dimension implications, Global Planet. Change, 50, 63-82, 2006.
HESSD

4, 4361-4387, 2007

\section{Extreme tidal levels in the Pearl River Delta}

Y. D. Chen et al.

\section{Title Page}

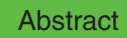

Introduction

Conclusions

Tables

References

Figures

14

$\rightarrow$

Back

Close

\section{Full Screen / Esc}

Printer-friendly Version

Interactive Discussion 
Huang, Z. G., Zhang, W. Q., Lai, G. W., Luo, X. T., Fan, J. C., and Jiang, P. L.: The Influence of Sea Level Rising on the Embankments in the Zhujiang Delta, Acta Geographica Sinica, 54(6), 518-525, 1999 (in Chinese).

Huang, Z. G., Zhang, W. Q., Wu, H. S., Fan, J. C., Jiang, P. L., Chen, T. G., Li, Z. H., and Huang,

$5 \quad$ B. S.: Prediction of the increasing magnitude of the sea level in the Pearl River Delta in 2030 and possible mitigation measures, Sci. China Ser. D, 30(2), 202-208, 2000 (in Chinese).

$\mathrm{Li}, \mathrm{T}$. J.: Analysis on hydrological factors and geomorphologic change of rivers, Guangdong Water Resources and Hydro-electrics (suppl.), 32-33, 2001 (in Chinese).

Liu, Y. H., Chen, X. H., Chen, Y. Q., and Zeng, C. H.: Correlation analysis on abnormal change of flood level in the central area of the Pearl River Delta, Tropical Geography, 23(3), 204-208, 2003 (in Chinese).

Luo, Z. R., Yang, S. Q., Luo, X. L., and Yang, G. R.: Dredging at Pearl River mouth and its dynamical and geomorphologic effects, Tropical Geomorphology, 21(1-2), 15-20, 2000 (in Chinese).

15 Mao, Q. W., Shi, P., Yin, K. D., Gan, J. P., and Qi, Y. Q.: Tides and tidal currents in the Pearl River Estuary, Cont. Shelf Res., 24, 1797-1808, 2004.

Pont, D., Day, J. W., Hensel, P., Franquet, E., Torre, F., Rioual, P., Ibanez, C., and Coulet, E.: response scenarios for the deltaic plain of the Rhone in the face of an accelerated rate of sea-level rise with special attention to Salicornia-type environments, Estuaries, 25, 337-358, $20 \quad 2002$

Wang, Z. L., Chen, X. H., Zhang, L., and Li, Y.: Spatio-temporal change characteristics of precipitation in the Pearl River basin in recent 40 years, Journal of China Hydrology, 26(6), 71-75, 2006 (in Chinese).

Wigley, T.: Impact of extreme events, Nature, 316, 106-107, 1985.

Xu, C.-Y.: Statistical analysis of a conceptual water balance model, methodology and case study, Water Resour. Manag., 15, 75-92, 2001.

$\mathrm{Xu}, \mathrm{H}$. L.: The preliminary study on environmental change of estuary and its hydrological modeling: a case study of Zhujiang Estuary, Tropical Geography, 18(2), 162-167, 1998 (in Chinese).

so Yang, Q. S., Shen, H. T., Luo, X. L., Luo, Z. R., Yang, G. R., and Ou, S. Y.: The secular trend of water level changes in the network channels of the Zhujiang River (Pearl River) Delta, Acta Oceanologica Sinica, 24(2), 30-37, 2002 (in Chinese).

Yoo, C.: Long term analysis of wet and dry years in Seoul, Korea, J. Hydrol., 318, 24-36, 2006.

HESSD

4, 4361-4387, 2007

\section{Extreme tidal levels in the Pearl River Delta}

Y. D. Chen et al.

Title Page

Abstract

Conclusions

Tables

Figures

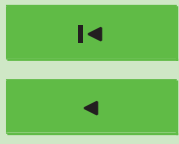

$\rightarrow$

Back

Close

Printer-friendly Version

Interactive Discussion 
Zhang, Q., Gemmer, M., and Chen, J. Q.: Climate changes and flood/drought risk in the Yangtze Delta, China, during the past millennium, Quatern. Int., doi:10.1016/j.quaint.2006.11.004, in press, 2007.

Zhang, Q., Liu, C.-L., and Xu, C.-Y.: Observed trends of annual maximum water level and 5 streamflow during past 130 years in the Yangtze River basin, China, J. Hydrol., 324, 255265, 2006.

Zhang, Q., Zhu, C., Liu, C. L., and Jiang, T.: Environmental change and its impacts on human settlement in the Yangtze Delta, P. R. China, Catena, 60, 267-277, 2005.

\section{HESSD}

4, 4361-4387, 2007

Extreme tidal levels in the Pearl River Delta

Y. D. Chen et al.

\section{Title Page}

Abstract

Introduction

Conclusions

References

Tables

Figures

14

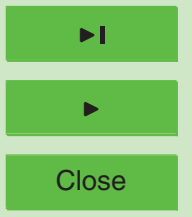

Back 
Table 1. Dataset of the water levels in the Pearl River Delta and the river channels where the gauging stations are located along.

\begin{tabular}{|c|c|c|c|c|c|c|}
\hline & Station name & Longitude & Latitude & Series length & Missing data & River channels \\
\hline Upper & Sanshui & $112^{\circ} 50^{\prime}$ & $23^{\circ} 10^{\prime}$ & 1958-2005 & Sep-Dec 1959; 1960 & Beijiang channel \\
\hline \multirow[t]{2}{*}{ PRD } & Makou & $112^{\circ} 48^{\prime}$ & $23^{\circ} 07^{\prime}$ & 1958-2006 & $\begin{array}{l}\text { Sep-Dec 1959; 1966; } \\
\text { 1968; Oct-Dec } 1969\end{array}$ & Xijiang channel \\
\hline & Shilong & $113^{\circ} 51^{\prime}$ & $23^{\circ} 07^{\prime}$ & 1980-2005 & & North mainstem East River \\
\hline Middle & Jiangmen & $113^{\circ} 07^{\prime}$ & $22^{\circ} 36^{\prime}$ & 1958-2005 & 2000 & Xijiang channel \\
\hline \multirow[t]{7}{*}{ PRD } & Laoyagang & $113^{\circ} 12^{\prime}$ & $23^{\circ} 14^{\prime}$ & 1958-2005 & \multirow[t]{4}{*}{ Dec 1959} & Xi'nanyong channel \\
\hline & Nanhua & $113^{\circ} 05^{\prime}$ & $22^{\circ} 48^{\prime}$ & 1958-2005 & & Ronggui channel \\
\hline & Rongqi & $113^{\circ} 16^{\prime}$ & $22^{\circ} 47^{\prime}$ & 1958-2005 & & Ronggui channel \\
\hline & Sanduo & $112^{\circ} 59^{\prime}$ & $22^{\circ} 59^{\prime}$ & 1958-2005 & & Shunde channel \\
\hline & Shizui & $112^{\circ} 54^{\prime}$ & $22^{\circ} 28^{\prime}$ & 1959-2005 & \multirow[t]{3}{*}{ Nov-Dec 1968; 2000} & Tanjiang channel \\
\hline & Tianhe & $113^{\circ} 04^{\prime}$ & $22^{\circ} 44^{\prime}$ & $1958-1988$ & & Xijiang channel \\
\hline & Xiaolan & $113^{\circ} 14^{\prime}$ & $22^{\circ} 41^{\prime}$ & 1975-2005 & & Xiaolan channel \\
\hline Lower & Dasheng & $113^{\circ} 32^{\prime}$ & $23^{\circ} 03^{\prime}$ & 1958-2005 & June-Dec 1963 & North mainstem East River \\
\hline \multirow[t]{11}{*}{ PRD } & Denglongshan & $113^{\circ} 24^{\prime}$ & $22^{\circ} 14^{\prime}$ & 1959-2005 & Jan-Sep 1958 & Modaomen channel \\
\hline & Hengmen & $113^{\circ} 31^{\prime}$ & $22^{\circ} 35^{\prime}$ & 1959-2005 & & Hengmen channel \\
\hline & Huangchong & $113^{\circ} 04^{\prime}$ & $22^{\circ} 18^{\prime}$ & 1961-2005 & \multirow[t]{4}{*}{ 2000-2005 } & Yamen channel \\
\hline & Huangjin & $113^{\circ} 17^{\prime}$ & $22^{\circ} 08^{\prime}$ & 1965-2005 & & Jitimen channel \\
\hline & Huangpu & $113^{\circ} 28^{\prime}$ & $23^{\circ} 06^{\prime}$ & 1958-2005 & & Qianhangxian channel \\
\hline & Nansha & $113^{\circ} 34^{\prime}$ & $22^{\circ} 45^{\prime}$ & 1963-2005 & & Jiaomen channel \\
\hline & Sanshakou & $113^{\circ} 30^{\prime}$ & $22^{\circ} 54^{\prime}$ & 1958-2005 & 1959 & Shawan channel \\
\hline & Sishengwei & $113^{\circ} 36^{\prime}$ & $22^{\circ} 55^{\prime}$ & 1958-2005 & 1964 & South mainstem East River \\
\hline & Wanqingshaxi & $113^{\circ} 31^{\prime}$ & $22^{\circ} 41^{\prime}$ & $1958-2005$ & $\begin{array}{l}\text { 1966-1967; 1985-1988; } \\
1996-1998\end{array}$ & Hongqili channel \\
\hline & Xipaotai & $113^{\circ} 07^{\prime}$ & $22^{\circ} 13^{\prime}$ & 1958-2005 & $1968-1973$ & Hutiaomen channel \\
\hline & Zhuyin & $113^{\circ} 17^{\prime}$ & $22^{\circ} 22^{\prime}$ & 1959-2005 & & Modaomen channel \\
\hline
\end{tabular}

\section{4, 4361-4387, 2007}

\section{Extreme tidal levels in the Pearl River Delta}

Y. D. Chen et al.

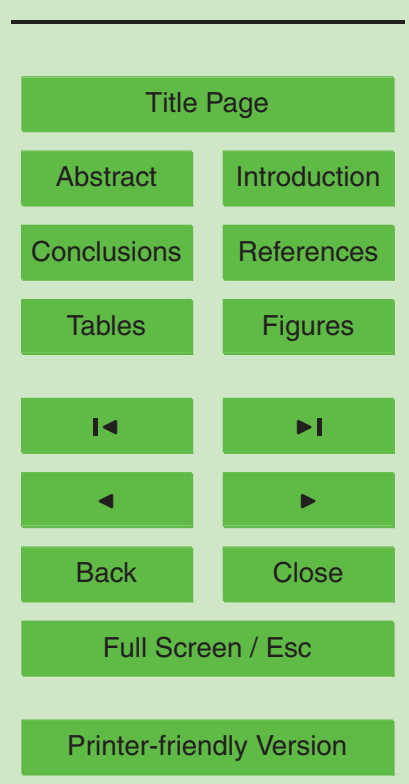

Interactive Discussion 
Table 2. Mean and standard deviation of high/low water level of the PRD.

\section{HESSD}

\begin{tabular}{llccrc}
\hline & Station name & \multicolumn{2}{c}{ High water level } & \multicolumn{2}{c}{ Low water level } \\
& & mean & std & mean & std \\
\hline Upper PRD & Sanshui & 3.15 & 2.27 & 0.54 & 0.89 \\
& Makou & 2.99 & 2.21 & 0.50 & 0.83 \\
& Shilong & 1.92 & 0.80 & -0.14 & 0.53 \\
\hline Middle PRD & Jiangmen & 1.70 & 0.90 & -0.10 & 0.45 \\
& Laoyagang & 1.44 & 0.35 & -0.83 & 0.20 \\
& Nanhua & 1.98 & 1.14 & 0.00 & 0.51 \\
& Rongqi & 1.60 & 0.55 & -0.51 & 0.33 \\
& Sanduo & 2.15 & 1.36 & -0.12 & 0.52 \\
& Shizui & 1.42 & 0.24 & -1.25 & 0.20 \\
& Tianhe & 2.05 & 1.23 & 0.11 & 0.54 \\
& Xiaolan & 1.74 & 0.79 & -0.24 & 0.37 \\
\hline Lower PRD & Dasheng & 1.52 & 0.23 & -1.42 & 0.17 \\
& Denglongshan & 1.21 & 0.23 & -0.76 & 0.19 \\
& Hengmen & 1.41 & 0.24 & -0.83 & 0.17 \\
& Huangchong & 1.39 & 0.22 & -1.20 & 0.16 \\
& Huangjin & 1.23 & 0.28 & -1.12 & 0.20 \\
& Huangpu & 1.54 & 0.23 & -1.48 & 0.16 \\
& Nansha & 1.46 & 0.24 & -1.10 & 0.19 \\
Sanshakou & 1.40 & 0.23 & -1.46 & 0.17 \\
& Sishengwei & 1.51 & 0.24 & -1.52 & 0.15 \\
Wanqingshaxi & 1.45 & 0.25 & -0.95 & 0.21 \\
Xipaotai & 1.38 & 0.23 & -1.13 & 0.17 \\
Zhuyin & 1.25 & 0.33 & -0.51 & 0.26 \\
\hline
\end{tabular}

4, 4361-4387, 2007

Extreme tidal levels in the Pearl River Delta

Y. D. Chen et al.

Title Page

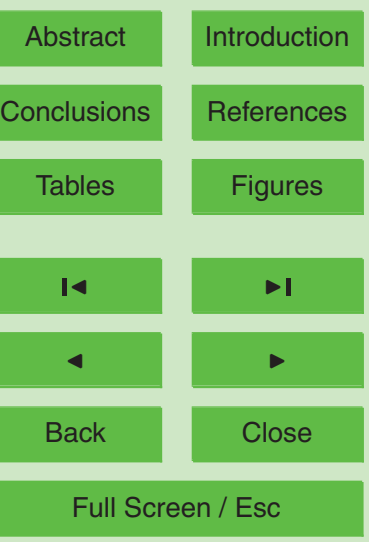

Printer-friendly Version

Interactive Discussion 
Table 3. Summary of the behaviors of the high/low water levels of the PRD.

\begin{tabular}{|c|c|c|c|c|c|c|c|}
\hline & \multirow[t]{2}{*}{ Station name } & \multicolumn{2}{|c|}{ High water level } & \multirow[t]{2}{*}{ final behavior } & \multicolumn{2}{|c|}{ Low water level } & \multirow[t]{2}{*}{ final behavior } \\
\hline & & HWLa & HWLb & & LWLa & LWLb & \\
\hline \multirow[t]{3}{*}{ Upper PRD } & Sanshui & $\theta$ & $\downarrow$ & $\equiv$ & $\downarrow$ & $\uparrow$ & $\downarrow$ \\
\hline & Makou & $\downarrow$ & $\downarrow$ & $\Xi$ & $\downarrow$ & $\uparrow$ & $\downarrow$ \\
\hline & Shilong & $\downarrow$ & $\uparrow$ & $\downarrow$ & $\downarrow$ & $\uparrow$ & $\downarrow$ \\
\hline \multirow[t]{8}{*}{ Middle PRD } & Jiangmen & $\ominus$ & $\uparrow$ & $\downarrow$ & $\downarrow$ & $\uparrow$ & $\downarrow$ \\
\hline & Laoyagang & $\theta$ & $\downarrow$ & $\Xi$ & $\downarrow$ & $\theta$ & $\Xi$ \\
\hline & Nanhua & $\ominus$ & $\downarrow$ & $\equiv$ & $\downarrow$ & $\uparrow$ & $\downarrow$ \\
\hline & Rongqi & $\theta$ & $\downarrow$ & $\Xi$ & $\theta$ & $\theta$ & $?$ \\
\hline & Sanduo & $\downarrow$ & $\ominus$ & $\Xi$ & $\downarrow$ & $\uparrow$ & $\downarrow$ \\
\hline & Shizui & $\ominus$ & $\ominus$ & $?$ & $\uparrow$ & $\downarrow$ & $\uparrow$ \\
\hline & Tianhe & $\theta$ & $\theta$ & $?$ & $\theta$ & $\downarrow$ & $\underline{\Xi}$ \\
\hline & Xiaolan & $\downarrow$ & $\ominus$ & $\Xi$ & $\ominus$ & $\uparrow$ & $\downarrow$ \\
\hline \multirow[t]{12}{*}{ Lower PRD } & Dasheng & $\theta$ & $\downarrow$ & $\Xi$ & $\bar{\uparrow}$ & $\downarrow$ & $\uparrow \uparrow$ \\
\hline & Denglongshan & $\theta$ & $\theta$ & $?$ & $\downarrow$ & $\uparrow$ & $\downarrow$ \\
\hline & Hengmen & $\uparrow$ & $\downarrow$ & $\uparrow$ & $\uparrow$ & $\downarrow$ & $\uparrow$ \\
\hline & Huangchong & $\theta$ & $\theta$ & $?$ & $\theta$ & $\downarrow$ & $\equiv$ \\
\hline & Huangjin & $\theta$ & $\downarrow$ & $\equiv$ & $\uparrow$ & $\downarrow$ & $\uparrow$ \\
\hline & Huangpu & $\ominus$ & $\downarrow$ & $\equiv$ & $\theta$ & $\downarrow$ & $\Xi$ \\
\hline & Nansha & $\theta$ & $\theta$ & $?$ & $\uparrow$ & $\downarrow$ & $\uparrow$ \\
\hline & Sanshakou & $\downarrow$ & $\uparrow$ & $\downarrow$ & $\downarrow$ & $\uparrow$ & $\downarrow$ \\
\hline & Sishengwei & $\uparrow$ & $\downarrow$ & $\uparrow$ & $\uparrow$ & $\downarrow$ & $\uparrow$ \\
\hline & Wangingshaxi & $\theta$ & $\downarrow$ & 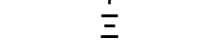 & $\uparrow$ & $\downarrow$ & $\uparrow$ \\
\hline & Xipaotai & $\uparrow$ & $\theta$ & $\uparrow$ & $\downarrow$ & $\uparrow$ & $\downarrow$ \\
\hline & Zhuyin & $\theta$ & $\downarrow$ & $\underline{\frac{1}{3}}$ & $\downarrow$ & $\uparrow$ & $\downarrow$ \\
\hline
\end{tabular}

Note: $\ominus$ : no trend; $\uparrow:$ significant increasing trend; $\downarrow$ : significant decreasing trend; $\Xi:$ decreasing variability; ?: not confirmative conclusion.
HESSD

4, 4361-4387, 2007

\section{Extreme tidal levels in the Pearl River Delta}

Y. D. Chen et al.

\section{Title Page}

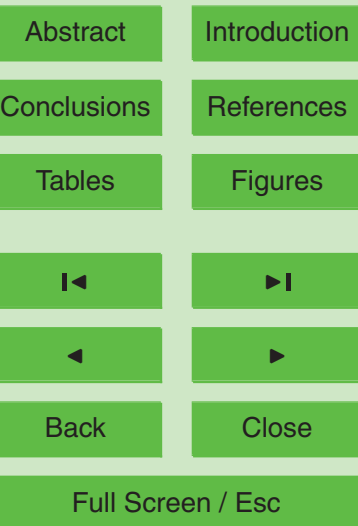

Printer-friendly Version

Interactive Discussion 


\section{HESSD}

4, 4361-4387, 2007

Table 4. Correlations between high/low water level of the PRD with the high/low flow of the Makou and Sanshui station. The values in the table are correlation coefficient, $R$.

\begin{tabular}{llllll}
\hline & Station & \multicolumn{2}{c}{$\begin{array}{c}\text { High water level } \\
\text { Makou }\end{array}$} & $\begin{array}{c}\text { Sanshui } \\
\text { Makou }\end{array}$ & Sanshui \\
\hline \multirow{2}{*}{ Upper PRD } & Makou & 0.95 & 0.89 & 0.78 & 0.58 \\
& Sanshui & 0.94 & 0.88 & 0.79 & 0.58 \\
\hline Middle PRD & Tianhe & 0.94 & 0.92 & 0.78 & 0.73 \\
& Xiaolan & 0.94 & 0.91 & 0.83 & 0.7 \\
& Nanhua & 0.91 & 0.9 & 0.79 & 0.63 \\
& Sanduo & 0.9 & 0.9 & 0.78 & 0.64 \\
& Rongqi & 0.9 & 0.88 & 0.77 & 0.67 \\
& Jiangmen & 0.9 & 0.85 & 0.76 & 0.62 \\
\hline Lower PRD & Zhuyin & 0.73 & 0.69 & 0.7 & 0.57 \\
& Nansha & 0.54 & 0.49 & 0.54 & 0.46 \\
& Sanshakou & 0.5 & 0.4 & 0.46 & 0.3 \\
& Hengmen & 0.5 & 0.5 & 0.55 & 0.53 \\
& Denglongshan & 0.45 & 0.41 & 0.48 & 0.396 \\
& Huangjin & 0.28 & 0.26 & 0.32 & 0.3 \\
\hline
\end{tabular}

Extreme tidal levels in the Pearl River Delta

Y. D. Chen et al.

Title Page

Abstract

Introduction

Conclusions

References

Tables

Figures

14

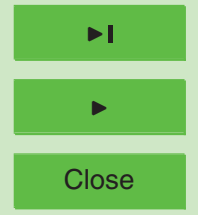

Back

Close

Full Screen / Esc

Printer-friendly Version

Interactive Discussion 


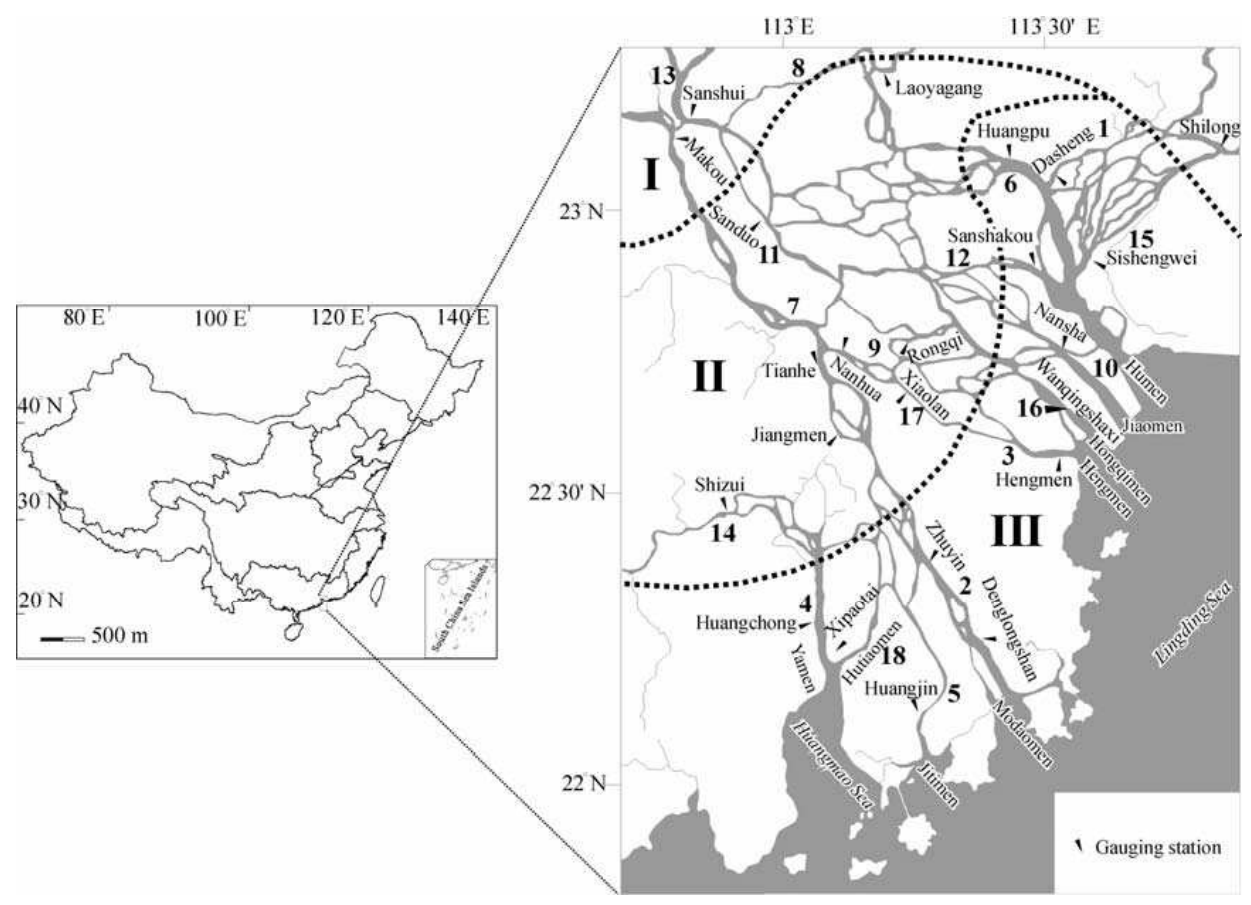

Fig. 1. Location of the Pearl River Delta in China and gauging stations. The river channels denoted with numbers are where the gauging stations are located. The names of the river channels are listed as following: 1: North mainstem East River; 2: Modaomen channel; 3: Hengmen channel; 4: Yamen channel; 5: Jitimen channel; 6: Qianhangxian channel; 7: Xijiang channel; 8: Xi'nanyong channel; 9: Ronggui channel; 10: Jiaomen channel; 11: Shunde channel; 12: Shawan channel; 13: Beijiang Channel; 14: Tanjiang channel; 15: South mainstem East River; 16: Hongqili channel; 17: Xiaolan channel; 18: Hutiaomen channel. The Pearl River Delta is divided into three parts based on its geomorphology as: I: the upper Pearl River Delta; II: the middle Pearl River Delta and III: the lower Pearl River Delta. Region I, region II and region III divided by dashed lines are the upper, middle and lower PRD.
HESSD

4, 4361-4387, 2007

\section{Extreme tidal levels in the Pearl River Delta}

Y. D. Chen et al.

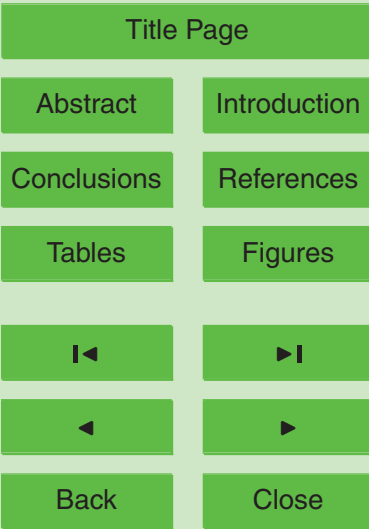

Full Screen / Esc

Printer-friendly Version

Interactive Discussion 


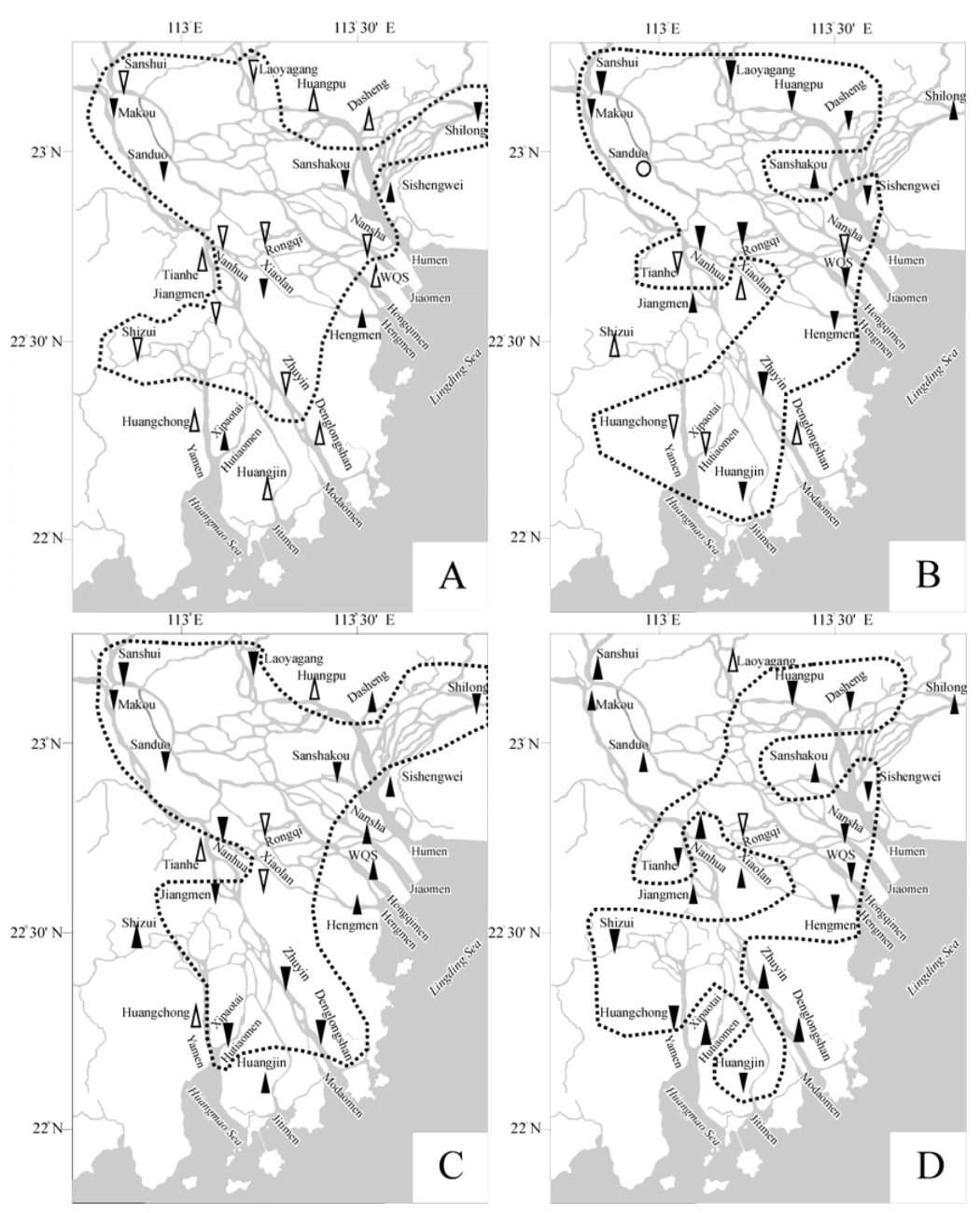

\section{HESSD}

4, 4361-4387, 2007

\section{Extreme tidal levels in the Pearl River Delta}

Y. D. Chen et al.

Title Page

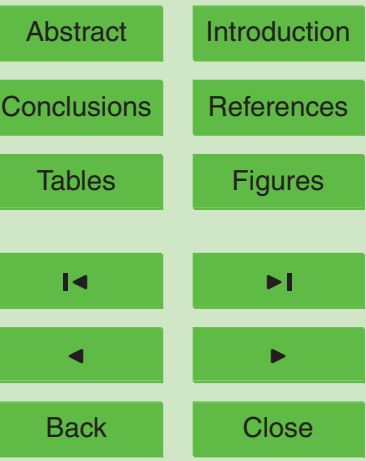

Full Screen / Esc

Printer-friendly Version

Interactive Discussion

EGU

Fig. 2. 


\section{HESSD}

4, 4361-4387, 2007

\section{Extreme tidal levels \\ in the Pearl River \\ Delta}

Y. D. Chen et al.

Fig. 2. Annual variability of the relative frequency of the extreme water levels exceeding/ falling below certain thresholds. (A): The trends of the relative frequency of the extreme high water level exceeding mean + std threshold; (B): The trends of the relative frequency of the extreme high water level falling below mean - std threshold; (C): The trends of the relative frequency of the extreme low water level exceeding mean + std threshold; and (D): The trends of the relative frequency of the extreme low water level falling below mean - std threshold. The triangles denote increasing/decreasing relative frequency of high/low water level (no trend); The solid triangles denote significant increasing/decreasing trend of the relative frequency of the high/low water level. The circles denote zero frequency. Stations dominated by decreasing water level are circled by dashed lines. WQS is the abbreviation of the Wangquanshaxi station.

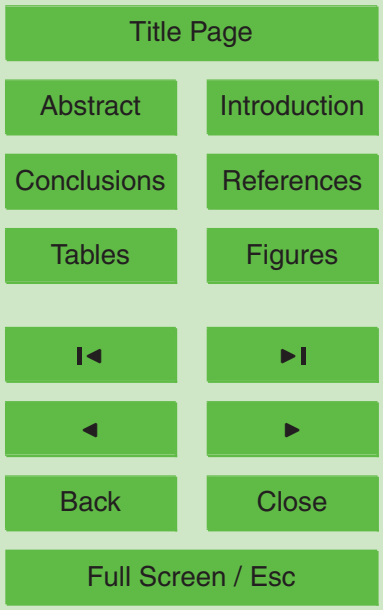

Printer-friendly Version

Interactive Discussion 


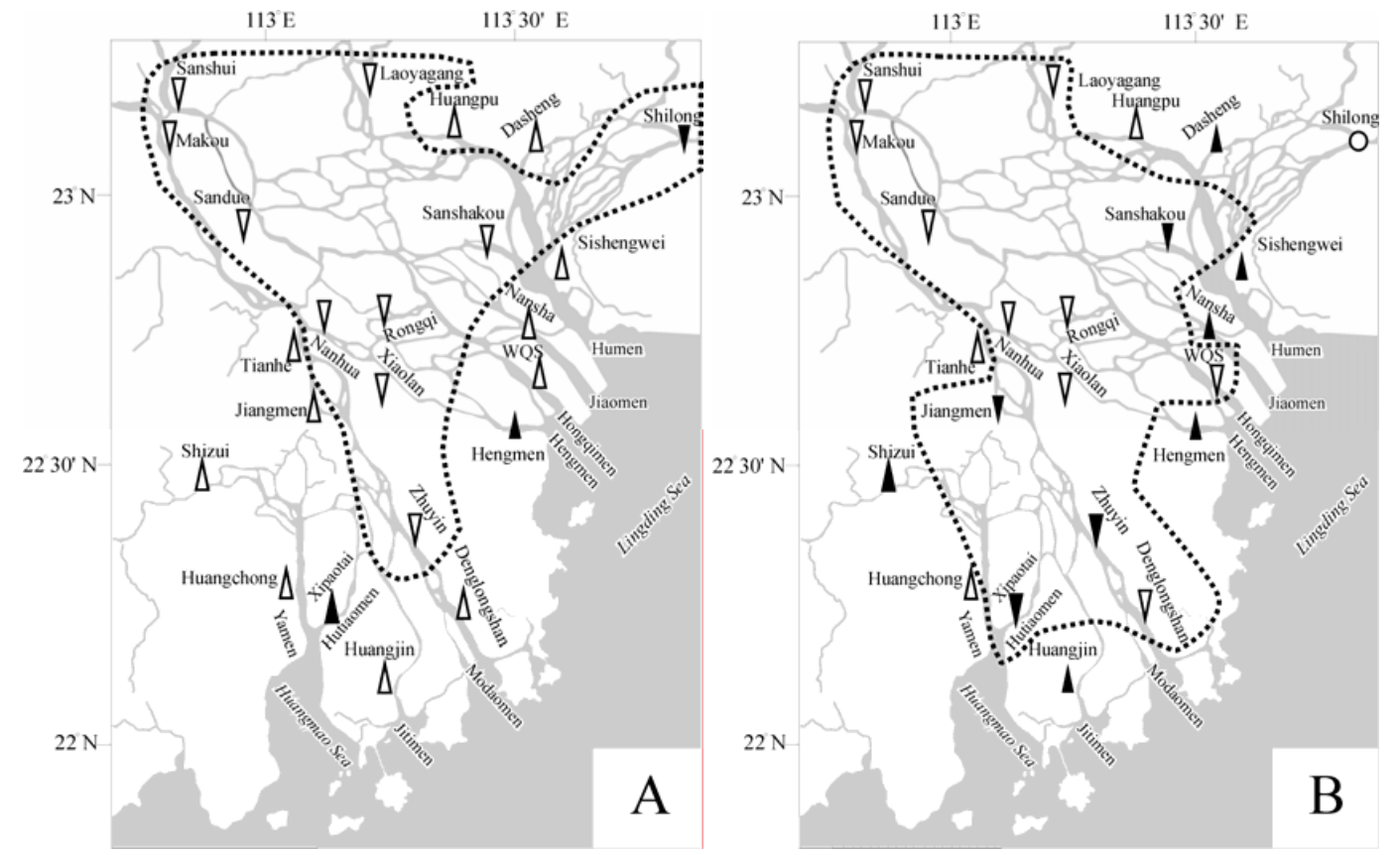

Fig. 3. Variations of the extreme high (A)/extreme low (B) water level exceeding mean + std threshold in summer. The triangles denote increasing/decreasing relative frequency of high/low water level (no trend); The solid triangles denote significant increasing/decreasing trend of the relative frequency of the high/low water level. The circles denote zero frequency. Stations dominated by decreasing water level are circled by dashed lines. WQS is the abbreviation of the Wangquanshaxi station.
HESSD

4, 4361-4387, 2007

\section{Extreme tidal levels in the Pearl River Delta}

Y. D. Chen et al.

\section{Title Page}

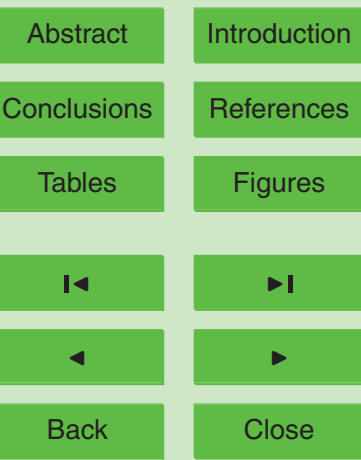

Full Screen / Esc

Printer-friendly Version

Interactive Discussion 


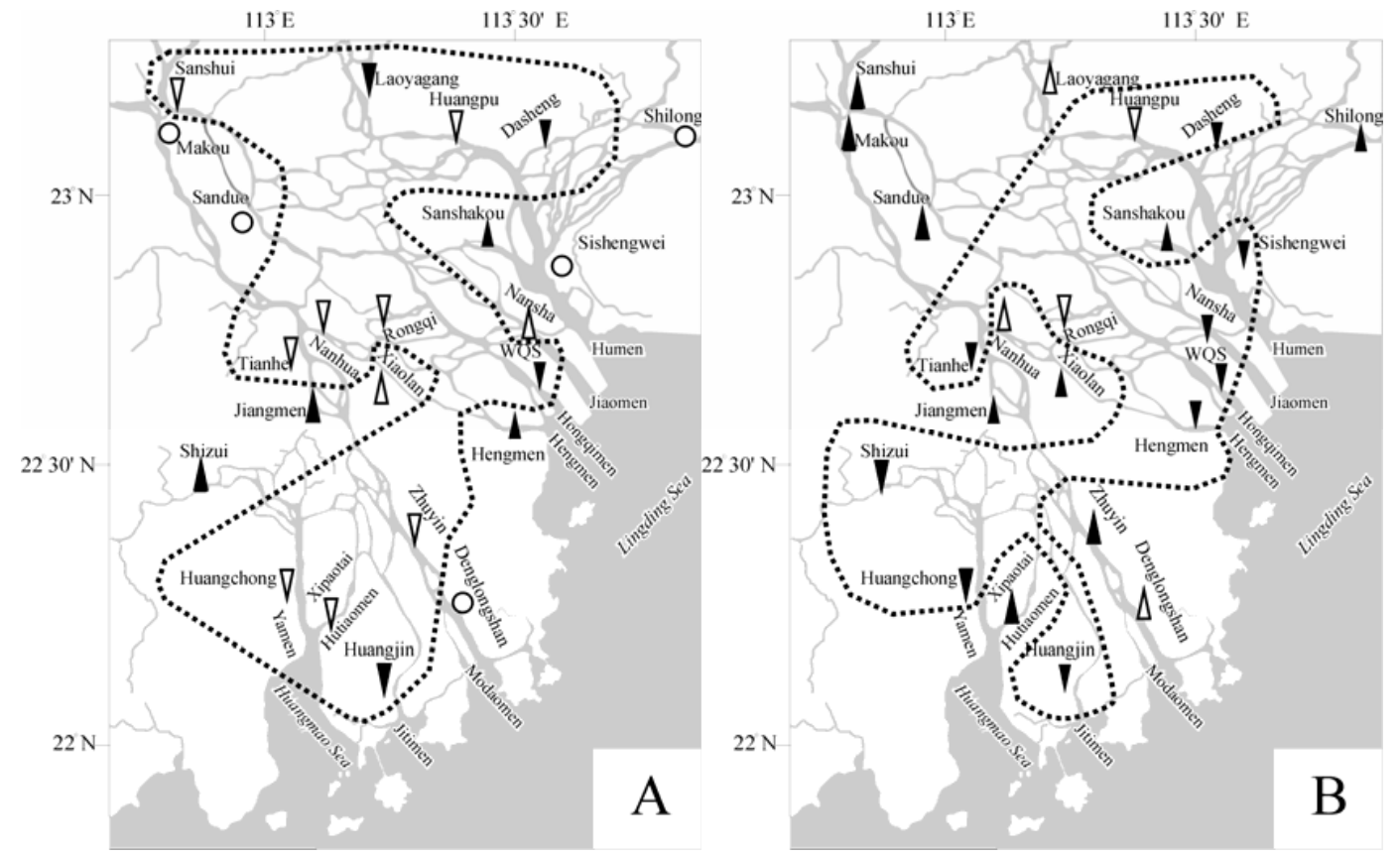

Fig. 4. Variations of the extreme high (A)/extreme low (B) water level falling below mean - std threshold in winter. The triangles denote increasing/decreasing relative frequency of high/low water level (no trend); The solid triangles denote significant increasing/decreasing trend of the relative frequency of the high/low water level. The circles denote zero frequency. Stations dominated by decreasing water level are circled by dashed lines. WQS is the abbreviation of the Wangquanshaxi station.

\section{HESSD}

4, 4361-4387, 2007

\section{Extreme tidal levels in the Pearl River Delta}

Y. D. Chen et al.

\section{Title Page}

Abstract

Introduction

Conclusions

References

Tables

Figures

14

4

Back

Close

\section{Full Screen / Esc}

Printer-friendly Version

Interactive Discussion 


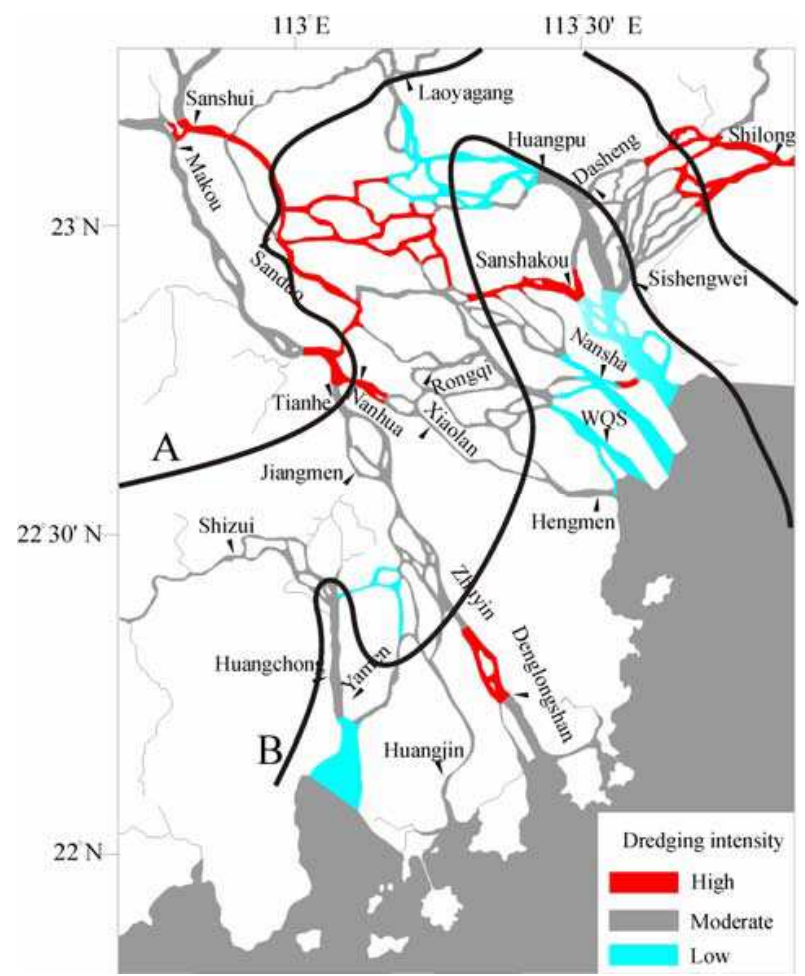

Fig. 5. River channels dominated by different intensity of the in-channel sand dredging. The solid lines marked with $A$ and $B$ show the demarcation of flood and flood-tidal areas (line A) and the demarcation of flood-tidal and tidal areas (line B) (after Huang et al., 1999). WQS: the Wanquanshaxi station.

\section{HESSD}

4, 4361-4387, 2007

Extreme tidal levels in the Pearl River Delta

Y. D. Chen et al.

\section{Title Page}

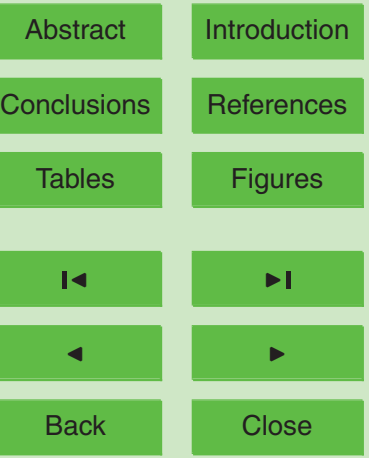

Full Screen / Esc

Printer-friendly Version

Interactive Discussion 